Gynecologic and

Obstetric Investigation
Gynecol Obstet Invest 2012;74:320-323

DOI: $\underline{10.1159 / 000339931}$
Received: July 26, 2011

Accepted after revision: June 3, 2012 Published online: August 16, 2012

\title{
Use of Balloon Tamponade in Management of Severe Vaginal Postpartum Hemorrhage and Vaginal Hematoma: A Case Series
}

\author{
Giuseppe Ghirardini $^{a} \quad$ Carlo Alboni ${ }^{a} \quad$ Mohamed Mabrouk ${ }^{a}$ b

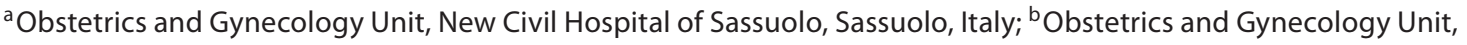 \\ University of Alexandria, Alexandria, Egypt
}

\section{Established Facts}

- Severe vaginal lacerations and hematomas can be serious, life-threatening complications of vaginal delivery.

- The management is usually limited to suturing and vaginal packing with gauze.

- Bleeding from multiple lacerations is difficult to control and suture. In these cases, hematoma formation is difficult to prevent, and when it occurs, its management is usually complex.

\section{Novel Insights}

- Vaginal balloon tamponade can be a solution in difficult cases of intractable vaginal hemorrhage or occult vaginal bleeding causing vaginal hematoma.

- A self-retaining vaginal balloon tamponade device can be a safe and effective solution. Vaginal balloon tamponade is well tolerated by the patients.

\section{Key Words}

Balloon tamponade - Postpartum • Vaginal hemorrhage • Vaginal hematoma

\section{Abstract}

Severe vaginal lacerations and hematomas can be serious, life-threatening complications of vaginal delivery. The management is usually limited to suturing and vaginal packing with gauze. After a vaginal delivery vaginal tissues can be edematous, friable and very difficult to suture. Vaginal balloon tamponade can be a solution in difficult cases of intractable vaginal hemorrhage or occult vaginal bleeding causing vaginal hematoma. We describe the use of a new balloon device for vaginal hemostasis in 4 cases to treat bleeding and prevent hematoma formation from postpartum vaginal lacerations. According to our experience, the use of this balloon tamponade system in treating severe vaginal postpartum hemorrhage seems to be safe, effective and well tolerated by the patients.

Copyright $\odot 2012$ S. Karger AG, Basel

\section{Introduction}

Postpartum vaginal hemorrhage (PPVH) remains a significant complication of childbirth and can be a lifethreatening condition for the mother. In particular,

\section{KARGER}

Fax +4161306 1234

E-Mail karger@karger.ch

www.karger.com
(C) 2012 S. Karger AG, Basel

0378-7346/12/0744-0320\$38.00/0

Accessible online at:

www.karger.com/goi
Dr. Carlo Alboni, MD

Obstetrics and Gynecology Unit, New Civil Hospital of Sassuolo

Via Ruini, 2

IT-41049 Sassuolo (Italy)

Tel. +390536846744, E-Mail carloalboni@libero.it 
bleeding from multiple mucosal lacerations is difficult to control and suture. In some patients, it is not possible to identify a submucosal bleeding vessel, hematoma formation is difficult to prevent, and when it occurs, its management is usually complex $[1,2]$.

Postpartum vaginal packing with gauze has been considered, until now, the treatment of choice in these cases. However, a long gauze used in such cases may absorb blood and conceal considerable blood loss. In addition, insertion and removal of vaginal gauze is not comfortable for a woman after vaginal birth, can cause scarring and adhesions.

The use of another type of vaginal balloon tamponade has been described in the literature and, to the best of our knowledge, there are only 2 reported cases of the use of a balloon in severe postpartum hemorrhage secondary to vaginal lacerations $[3,4]$. The balloon cited in these case reports is the Bakri postpartum balloon (Cook Medical, USA). It is an inflatable tamponade balloon usually used to control postpartum uterine hemorrhage. This disposable device is made of silicone rubber and, after placement inside the uterus, is filled with saline solution [5]. In 2007, Tattersall and Braithwaite [3] reported a case of a PPVH that occurred in a 17-year-old woman at first pregnancy, after an apparently uncomplicated spontaneous vaginal delivery, and was treated with the insertion in the vagina of two separate Bakri balloons inflated with saline and further labial suture to retain the balloons in the vagina. Yoong et al. [4], in 2009, reported a case of PPVH caused by multiple tears in an edematous and friable vaginal mucosa. The patient refused blood transfusion and after suturing, a Bakri balloon was placed in the vagina and filled with $100 \mathrm{ml}$ of saline followed by gauze packing to prevent expulsion of the device. The balloon controlled the bleeding and after $24 \mathrm{~h}$ was deflated and removed.

Here, we present our experience with balloon tamponade in PPVH using a new, self-retaining tamponade system, Vagistop ${ }^{\circledR}$ (RI.MOS., Medical Products, Mirandola, Italy), a balloon specifically created for vaginal distension and inspection (fig. 1).

\section{Characteristics and Method of Use of the Device}

The device is made of a flexible tube with a balloon tip, connectible to a syringe through a valve that allows inflating the balloon continuously, without pulling out the syringe. The balloon is inserted into the vagina towards the posterior vaginal fornix. After insertion, the balloon is inflated with air using a 50 - or $60-\mathrm{ml}$ syringe connected to the inflation tube trough the valve (fig. 1) until the whole vaginal space is occupied. The material of the sur- face of the balloon is a polymer that allows the device to adhere to vaginal walls, and after its inflation, it works as a self-retaining vaginal tamponade system. The total capacity of the balloon is $500 \mathrm{ml}$.

The balloon is deflated $24 \mathrm{~h}$ later and left in place for $1 \mathrm{~h}$, and when no further bleeding is observed, it is removed. In all cases, urinary catheter is inserted. For evaluation of the discomfort of the patient, a visual analog scale (VAS) score is used.

\section{Case Series}

Case 1

A 30-year-old primipara. After a spontaneous delivery of a 3,700-gram male, profuse vaginal bleeding was observed. After vaginal inspection, multiple superficial mucosal vaginal lacerations were found. The vaginal tissues were edematous and friable, so we decided not to suture the vaginal lacerations. Blood loss was about $800 \mathrm{ml}$. Hemoglobin ( $\mathrm{Hb}$ ) level was $8.9 \mathrm{~g} / \mathrm{dl}$. The device was inserted into the vagina, filled with $420 \mathrm{ml}$ of air (fig. 2) and removed after $24 \mathrm{~h}$. During its presence in the vagina, the patient did not complain of pain caused by the device. The VAS score was $0 / 10$. The difference in $\mathrm{Hb} 24 \mathrm{~h}$ postpartum $(\Delta \mathrm{Hb})$ was $0.3 \mathrm{~g} / \mathrm{dl}$. No further interventions were needed. At postpartum follow-up visit (after 50 days), vaginal mucosa was regular and no palpable fibrous tissue was detected at gynecologic examination.

Case 2

A 35-year-old woman, 2 gravida 1 para, underwent an operative delivery with vacuum extraction and right lateral episiotomy. The newborn's weight was 3,640 g. After delivery, vaginal exploration revealed a vaginal laceration of the left vaginal wall that extended to the left vaginal fornix. The lateral laceration and the episiotomy were sutured under local anesthesia in the delivery room. Vaginal blood loss was $70 \mathrm{ml}$ and the patient was transferred to the postnatal ward. Two hours after delivery, the patient reported a heavy increasing pain towards the left ischiorectal fossa. At vaginal examination, a huge hematoma of the left vaginal wall was detected. The Hb level dropped to $5.9 \mathrm{~g} / \mathrm{dl}$. The patient was transferred to the operating theater, and exploration under general anesthesia confirmed the presence of a hematoma of the left vaginal wall dissecting the left ischiorectal fossa. A surgical drainage of the hematoma was carried out, no bleeding vessel was identified after evacuation of the hematoma and we performed hemostasis and suture with interrupted stitches with absorbable 2-0 Vycril rapid (Ethicon, USA). We then applied the balloon, filled with $460 \mathrm{ml}$ of air; vaginal bleeding stopped and Vagistop was removed after $24 \mathrm{~h}$. VAS score was $0 / 10, \Delta \mathrm{Hb}$ was $0.1 \mathrm{~g} / \mathrm{dl}$ and no blood transfusion was needed. The patient was discharged on the 5 th day after delivery in good condition.

\section{Case 3}

A 34-year-old woman, 2 gravida 1 para, delivered a female newborn of 2,840 g. At the end of the second stage of labor, an episiotomy was performed. Following delivery, the patient had a profuse postpartum hemorrhage (total blood loss of 1,000 ml). 


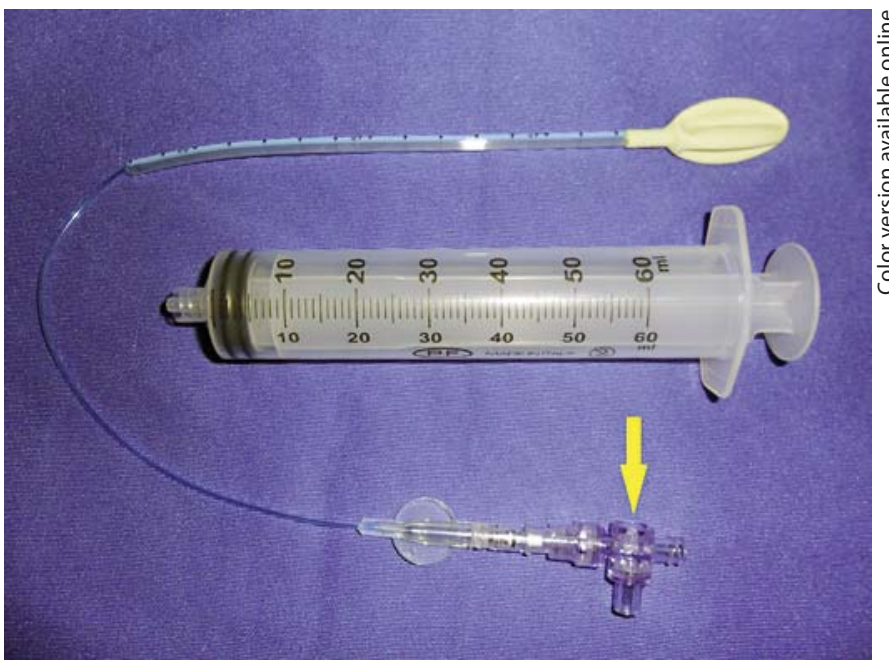

Fig. 1. Vagistop. The balloon tube is connected with a syringe trough a valve (arrow) that permits to inflate the balloon continuously, without pulling out the syringe.

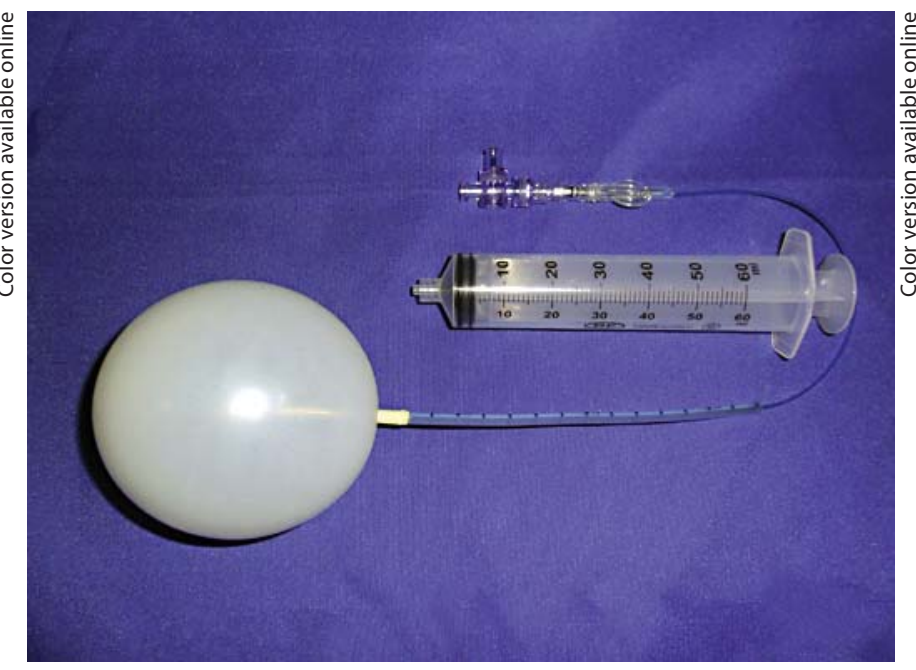

Fig. 2. Vagistop. The balloon is inflated with $420 \mathrm{ml}$ of air.

Table 1. Summary of the cases

\begin{tabular}{llllllll}
\hline Case & Age & Indication & Delivery & Birth weight, g & $\begin{array}{l}\text { Blood loss } \\
(\mathrm{PPH}), \mathrm{ml}\end{array}$ & Episiotomy & $\begin{array}{l}\text { Vaginal } \\
\text { suture }\end{array}$ \\
\hline 1 & 30 & Multiple lacerations & SD & 3,700 & 800 & No & No \\
2 & 35 & Vaginal hematoma & VAC & 3,640 & 70 & Yes & Yes \\
3 & 34 & Multiple lacerations & SD & 2,840 & 1,000 & Yes & Yes \\
4 & 38 & Vaginal hematoma & VAC & 3,110 & 650 & No & Yes \\
\hline
\end{tabular}

$\mathrm{SD}=$ Spontaneous delivery $\mathrm{VAC}=$ vacuum extraction; $\mathrm{PPH}=$ postpartum hemorrhage

The uterus was well contracted and at vaginal examination, two lacerations of the right and left vaginal walls that reached bilaterally both lateral vaginal fornices were observed. After suturing of vaginal lacerations, we did not reach a perfect hemostasis in the submucosal layers. Blood was coming to the vaginal mucosa from deeper layers, the vaginal mucosa was fragile and edematous, and so the balloon was inserted to prevent hematoma formation and filled with $360 \mathrm{ml}$ of air. The device was removed after $24 \mathrm{~h}$ with no hematomas at vaginal exploration. VAS score was $0 / 10, \Delta \mathrm{Hb}$ was $0.4 \mathrm{~g} / \mathrm{dl}$.

\section{Case 4}

A 38-year-old primigravida was assisted for a vacuum delivery. The weight of the infant was $3,110 \mathrm{~g}$. We performed a suture of a second-degree laceration of the left vaginal wall. Postpartum blood loss was approximately $650 \mathrm{ml}$. After $1 \mathrm{~h}$ of observation in the delivery room, the patient reported increasing pain from the site of the vaginal suture. She was transferred to the operating theater for examination under general anesthesia. A vaginal hematoma was drained, but no single bleeding vessel was seen. After suturing, Vagistop was inserted into the posterior vaginal fornix and inflated with $420 \mathrm{ml}$ of air. After $30 \mathrm{~min}$ of observation, no bleeding was observed and the patient was transferred to the postnatal ward. We removed the device after $24 \mathrm{~h}$ and no further bleeding was observed. The patient felt comfortable with the device (VAS score was $0 / 10$ ). $\Delta \mathrm{Hb}$ was $0.5 \mathrm{~g} / \mathrm{dl}$.

\section{Discussion}

In this case series, we have observed that balloon vaginal tamponade can be a useful intervention in the management of particular cases of PPVH and vaginal hematomas. Gauze packs can also be used for arresting bleeding, but they are potentially traumatic and time consuming. In addition, the gauze material absorbs blood and can give a false impression of bleeding control. 
Successful postpartum use of vaginal balloons to achieve hemostasis in cases of PPVH has been described in case reports. Nonetheless, balloon systems used were not originally designed for vaginal use, were not self-retaining and additional sutures or further packing were always needed to fix the balloon in place $[3,4]$.

In our series (table 1), the indications for balloon insertion were: multiple mucosal vaginal lacerations with edematous mucosa (case 1); evacuation of vaginal hematoma with inability to find a bleeding vessel and achieve proper hemostasis (cases 2 and 4), and failure to achieve hemostasis in submucosal layers after suturing vaginal lacerations with edematous mucosa (case 3 ).

The balloon described in our series is self-retaining and, hence, there was no need for further interventions to prevent slipping from the vagina. Being designed for vaginal use, the balloon can easily adjust to the vaginal walls and achieve the required intra-balloon pressure (about $50 \mathrm{~mm} \mathrm{Hg}$ ) necessary to achieve hemostasis. Furthermore, the non-absorbing nature of the balloon material allows blood to surge between the balloon and the vaginal walls and permits surveillance of further bleeding. The ease and rapidity of application can be considered additional advantages in cases of PPVH. The adaptability of the balloon, even with high pressure, to the vagina might be the reason of the good acceptance by the patients who did not report vaginal pain during the presence of the balloon.
It is important to emphasize that management of PPVH has to be in accordance with approved protocols for postpartum hemorrhage management. Examination under regional or general anesthesia is usually undertaken for identification of the cause and treatment of hemorrhage. Repair of vaginal trauma and accurate hemostasis are the best treatment for PPVH. In certain cases where vaginal mucosa is particularly edematous or when appropriate hemostasis cannot be achieved after hematoma formation or evacuation, the use of vaginal balloon tamponade can be a suitable solution.

It is clear that observations from this case series cannot be generalized due to the limited number of cases and the retrospective nature of data collection. An ideal study design to investigate this management modality for PPVH would be a randomized controlled trial. However, like in many other obstetric emergencies, such a study design is not easy to perform. Larger, prospective, multicenter studies are needed to evaluate the efficacy of this system in the management of PPVH.

In our experience, balloon tamponade with Vagistop seems to be successful in cases of postpartum hemorrhage secondary to vaginal mucosal lacerations, as well as in the prevention of vaginal hematomas. The potential for it to be applied by inexpert operators might make it a useful addition in the management of PPVH.

\section{References}

1 Mukherjee S, Arulkumaran S: Post-partum haemorrhage. Obstet Gynaecol Reprod Med 2009;19:121-126.

-2 Ridgway LE: Puerperal emergency. Vaginal and vulvar hematomas. Obstet Gynecol Clin North Am 1995;22:275-282.

- 3 Tattersall M, Braithwaite W: Balloon tamponade for vaginal lacerations causing severe postpartum haemorrhage. BJOG 2007; 114:647-648.
4 Yoong W, Ray A, Philip SA: Balloon tamponade for postpartum vaginal lacerations in a woman refusing blood transfusion. Int $\mathrm{J}$ Gynaecol Obstet 2009;106:261.

5 Bakri YN, Amri A, Jabbar FA: Tamponadeballoon for obstetrical bleeding. Int J Gynaecol Obstet 2001;74:139-142. 